\title{
Medication regimen complexity in institutionalized elderly people in an aging society
}

\section{Ana Margarida Advinha, Sofia de Oliveira-Martins, Vanessa Mateus, Sara Grou Pajote \& Manuel José Lopes}

International Journal of Clinical Pharmacy

International Journal of Clinical Pharmacy and Pharmaceutical Care

\section{ISSN 2210-7703}

Int J Clin Pharm

DOI 10.1007/s11096-014-9963-4

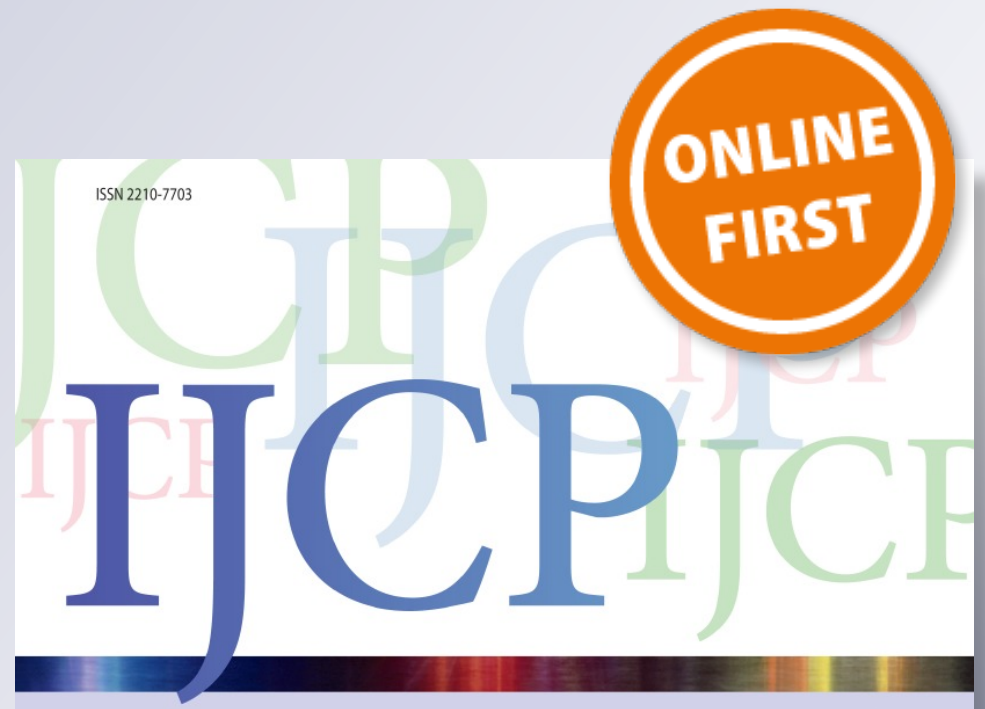

International Journal of Clinical Pharmacy

Official Scientific Journal of the Royal Dutch Association

for the Advancement of Pharmacy (KNMP)

and the European Society for Clinical Pharmacy (ESCP)

$\rightarrow$ KNMP РESCP

包 Springer

勿 Springer 
Your article is protected by copyright and all rights are held exclusively by Koninklijke Nederlandse Maatschappij ter bevordering der Pharmacie. This e-offprint is for personal use only and shall not be self-archived in electronic repositories. If you wish to self-archive your article, please use the accepted manuscript version for posting on your own website. You may further deposit the accepted manuscript version in any repository, provided it is only made publicly available 12 months after official publication or later and provided acknowledgement is given to the original source of publication and a link is inserted to the published article on Springer's website. The link must be accompanied by the following text: "The final publication is available at link.springer.com". 


\title{
Medication regimen complexity in institutionalized elderly people in an aging society
}

\author{
Ana Margarida Advinha $\cdot$ Sofia de Oliveira-Martins • \\ Vanessa Mateus · Sara Grou Pajote · \\ Manuel José Lopes
}

Received: 15 July 2013/Accepted: 20 May 2014

(C) Koninklijke Nederlandse Maatschappij ter bevordering der Pharmacie 2014

\begin{abstract}
Background Complex medication regimens may adversely affect compliance and treatment outcomes. Complexity can be assessed with the medication regimen complexity index (MRCI), which has proved to be a valid, reliable tool, with potential uses in both practice and research. Objective To use the MRCI to assess medication regimen complexity in institutionalized elderly people. Setting Five nursing homes in mainland Portugal. Methods A descriptive, cross-sectional study of institutionalized elderly people $(n=415)$ was performed from March to June 2009, including all inpatients aged 65 and over taking at least one medication per day. Main outcome measure Medication regimen complexity index. Results The mean age of the sample was 83.9 years ( \pm 6.6 years), and $60.2 \%$ were women. The elderly patients were taking a large number of drugs, with $76.6 \%$ taking more than five medications per day. The average medication regimen complexity was $18.2( \pm \mathrm{SD}=9.6)$, and was higher in the females $(p<0.001)$. The most decisive factors contributing to the complexity were the number of drugs and dosage frequency. In regimens with the same number of medications, schedule was the most relevant factor in the final
\end{abstract}

A. M. Advinha $(\bowtie) \cdot$ S. de Oliveira-Martins

iMed.UL - Instituto de Investigação do Medicamento, Faculty of Pharmacy of the University of Lisbon, Avenida Professor Gama Pinto, 1649-003 Lisbon, Portugal

e-mail: ana.advinha@gmail.com

V. Mateus

Lisbon School of Health Technology, Polytechnic Institute of Lisbon, Avenida D. João II, Lote 4.69.01, 1990-096 Lisbon, Portugal

S. G. Pajote - M. J. Lopes

College of Nursing S. João de Deus, University of Évora, Largo do Senhor da Pobreza, 7000-811 Évora, Portugal score $(\mathrm{r}=0.922)$, followed by pharmaceutical forms $(\mathrm{r}=0.768)$ and additional instructions $(\mathrm{r}=0.742)$. Conclusion Medication regimen complexity proved to be high. There is certainly potential for the pharmacist's intervention to reduce it as part as the medication review routine in all the patients.

Keywords Drug therapy complexity - Elderly $\cdot$ MRCI · Nursing homes · Portugal

\section{Impact of findings on practice statements}

- Regimen complexity assessment by clinicians and pharmacists should be a high priority in the management of institutionalized elderly patients.

- Nursing homes should consider conducting medication reviews in order to reduce the complexity of older patients' drug regimens.

- Educational sessions for managers, pharmacists, clinicians and patient attendants working at nursing homes would be of great value.

- MRCI could be an important tool in monitoring drug therapy complexity at nursing homes in Portugal and identifying the potential ways of reducing it.

\section{Introduction}

Demographic aging is a global phenomenon. The United Nations estimates that elderly people currently account for $11 \%$ of the total population (about 800 million), and an exponential increase is expected up to 2050 (about 2 billion) [1]. 
Portugal is among the most aging countries. According to the United Nations (which considers everyone aged 60 or over to be elderly), $24 \%$ of the Portuguese population was elderly in 2011. The 2011 National Census data (Statistics Portugal [2]) showed that there were about 129 elderly ( $\geq 65$ years) per 100 young people $(<15$ years), representing $19 \%$ of the total population [1-3].

The social transition that follows this phenomenon, at least in more developed countries, often conditions the possibility of aging in the family environment. Institutionalization of the elderly is frequently driven by a lack of domestic and social support and the admission in a care home is often the only way to have access to care and services, especially health, that they would otherwise not receive [4-6].

In most cases, aging is also synonymous with chronic diseases and consequently polypharmacy. Old people are the age group with highest consumption of medications. Polypharmacy is associated with adverse reactions, greater risk of hospitalization, poor adherence and unnecessary costs for the patient [7-10].

A large number of medications and complicated schedules or additional instructions can also contribute to the patient's increased difficulty or loss of interest in following treatment recommendations and therefore poor clinical outcomes [11]. The results of several studies have shown that adherence declines as medication regimen complexity increases and this complexity is one of the main root causes of patients' non-compliance. It may also result in medication errors-the more complex the regimen is to follow, the easier it is for the patient to get it wrong. Poor adherence and medication errors are a serious concern for health practitioners. They often lead to higher use of resources, owing to a reduction in effectiveness and increased risk of therapeutic failure [12-14].

Medication regimen complexity is therefore a major concern for patients with chronic diseases and their caregivers. The complexity of a person's medication regimen depends on the characteristics of the pharmacotherapy, such as the number of drugs consumed, their pharmaceutical forms, schedules and doses and additional instructions given by the physician. It can be measured with the medication regimen complexity index (MRCI), originally validated in English by George [15] and adapted to Portuguese by Melchiors [16]. The MRCI has proved to be a valid, reliable tool for quantifying medication regimen complexity. It is, fast (5-10 min) with potential use in both practice and research [15].

The MRCI is divided into three different sections, which contribute to the final score based on the weight of the tasks in the medication regimen. Section A covers pharmaceutical forms, Section B frequencies and Section $\mathrm{C}$ additional instructions. Each section has its own score and the final complexity score is the sum of the section subtotals [15].
Older people in residential aged-care facilities have many of the difficulties experienced by those in the community, but also encounter problems specific to that environment. In nursing homes medication regimen complexity and its problems arise not just from the medication taken but also other factors, such as lack of training of staff administering the medication, no pharmacovigilance and no medication follow-up or reviews [15-17].

Stange [18] and Elliott [19] identified dosing frequency as the simplification with the highest potential, especially in inpatients, followed by the number of dose units and the time of administration-Sections B and C of the MRCI.

Higher MRCI scores were associated with increased risk of emergency department visits and hospitalization, even after controlling for number of medications and case-mix (demographics, comorbidity and clinical and functional status) [20].

Simplification and greater attention to managing complexity are potentially remedial factors for poor adherence and medication errors, not only in community dwelling elders, but also in institutionalized patients. However, before remedial action can be taken, patients with complex management regimens must be identified.

\section{Aim of the study}

The aim of this study was to assess the medication regimen complexity of institutionalized elderly people, using the MRCI to identify the type of action with the highest potential for reducing complexity (according to the three MRCI sections) and contribute to rational use of medication in this frailer population.

\section{Method}

This descriptive, cross-sectional study was conducted in five nursing homes in mainland Portugal (Lisbon and Alentejo health regions) from March to June of 2009, and included all inpatients aged 65 and over and taking at least one medication a day (recorded in their medication schedule). Selection of the nursing homes was based on the following criteria: existence of written individual medication records, nursing and medical support and participation agreement in the study.

Data collection was based on the MRCI, but also included social, demographic and medication data.

The following factors were considered when scoring complexity: the number of medications in the regimen; their pharmaceutical forms (each different form represents a unit); the number of doses per day (each dose represents a unit); additional instructions (i.e. take with meals or break 
the tablet) (each instruction represents a unit). Additional instructions also include some mechanical means needed to administer medications, such as eye drops, inhalers or injections.

The MRCI is an open-ended index, so there is no limit to the total number of medications that can be included in it. The minimum MRCI score for someone on medication is 1.5 , which represents a single tablet or capsule taken once a day as needed, while there is no established maximum as the score increases with the number of medications.

Data were collected from the nursing home pharmacies and the form was filled out in two stages. The first was a transcription of each elderly patient's medication profile (approximately five minutes per individual) and the second was use of the MRCI scale to evaluate medication regimen complexity (approximately $10 \mathrm{~min}$ per individual profile). Polypharmacy was considered six or more drugs [21].

Statistical analysis was performed with the SPSS (v19). We considered a significance level of $p<0.05$ and a confidence interval of $95 \%$. All study variables, including baseline and outcome measures, were analyzed. For continuous measures, $p$ values represented an overall $\mathrm{F}$ test of the means. For categorical variables, a Chi square test was performed to assess statistical significance.

In accordance with the Helsinki Declaration, informed consent was obtained for collecting and processing information and data confidentiality was ensured. Ethical approval of the research was obtained from the institutions involved. The results of the performed assessment were left to the health professionals in charge of the medication management of the involved Institutions, in order to allow the implementation of interventions, aiming to reduce the regimen complexity, when applicable.

\section{Results}

Patient profiles

Data was collected from 415 elderly patients. The sample's mean age was 83.9 years ( \pm 6.6 years), and $60.2 \%$ were women. Mean age by gender was 84.3 years ( \pm 6.2 years) for women and 83.4 years ( \pm 7.1 years) for men (Table 1$)$.

\section{Medication profile}

The sample $(\mathrm{n}=415)$ took a total of 3,410 medications and average consumption was $8.2( \pm 3.6)$ drugs per individual per day, with a minimum of 1 and a maximum of 20 . Mean daily consumption was higher in females $(8.9 \pm 3.4$ drugs) than in males at 7.2 drugs $( \pm 3.6)$ per day $(\mathrm{p}<0.001)$. The majority of the sample $(85.5 \%)$ was under polypharmacy.
Table 1 Socio demographic characterization of the sample

\begin{tabular}{lc}
\hline Variables & Frequency $(\mathrm{N}=415) \%$ \\
\hline Gender & \\
Female & 60.2 \\
Male & 39.8 \\
Age group & \\
65-74 years & \\
$75-84$ years & 9.6 \\
$\geq 85$ years & 40.5 \\
\hline
\end{tabular}

Table 2 Medication profile

\begin{tabular}{ll}
\hline Variables & Frequency $\%$ \\
\hline Daily consumption of drugs & $(\mathrm{n}=415)$ \\
(01-05 drugs) & 23.4 \\
(06-10 drugs) & 51.8 \\
(11-15 drugs) & 21.2 \\
(16-20 drugs) & 3.6 \\
Dosage forms & $(\mathrm{n}=3,410)$ \\
Tablets and capsules & 84.5 \\
Oral solutions & 3.1 \\
Powders and granules & 2.9 \\
Topicals (excl. Patches) & 2.6 \\
Patches & 1.5 \\
Eye drops and creams/ear drops & 1.5 \\
Nasal spray & 0.2 \\
Inhalers & 2.6 \\
Injections & 0.9 \\
Enemas and suppositories & 0.2 \\
Pharmacotherapeutic groups & $(\mathrm{n}=3,410)$ \\
Cardivascular system & 30.8 \\
Nervous system & 27.7 \\
Metabolism and alimentary tract & 16.4 \\
Blood & 7.8 \\
Respiratory system & 4.3 \\
Others & 13.0 \\
\hline & \\
&
\end{tabular}

Table 2 shows the sample's drug consumption, pharmaceutical forms and therapeutic groups.

Cardiovascular system (30.8\%), nervous system $(27.7 \%)$ and metabolism and alimentary tract $(16.4 \%)$ were the most common groups.

In the sample, $88.2 \%(366 / 415)$ of the elderly were taking at least one cardiovascular drug, $83.4 \%$ (346/415) at least one drug for the nervous system and $70.1 \%$ (291/ 415 ) at least one drug for the metabolism and alimentary tract.

The top five active substances were low-dosage aspirin $-31.8 \%(132 / 415)$, simvastatin $-28.2 \%$ (117/415), 
Table 3 Medication regimen complexity index by sections (mean scores)

\begin{tabular}{lrll}
\hline MRCI profile & & & \\
\hline MRCI total score & Mean (SD) & Minimum & Maximum \\
\hline MRCI section A score & $3.6(3.1)$ & 1.0 & 20.0 \\
MRCI section B score & $11.2(5.4)$ & 0.5 & 28.0 \\
MRCI section C score & $3.4(3.0)$ & 0 & 15.0 \\
MRCI total score & $18.2(9.6)$ & 2.0 & 53.5
\end{tabular}

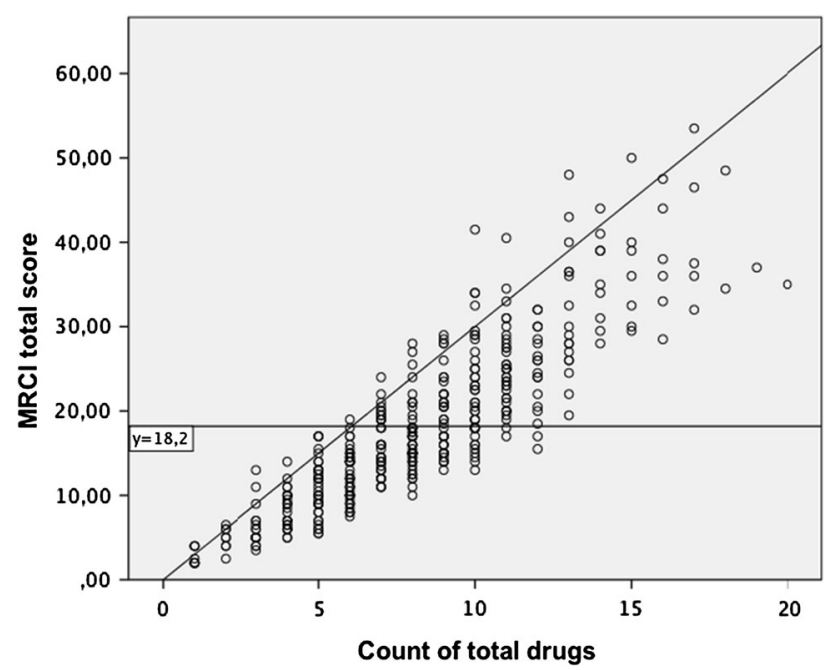

Fig. 1 Scatterplot of medication regimen complexity index scores according to the number of consumed drugs

furosemide $-22.9 \%(95 / 415)$, omeprazole-17.1\% (71/ $415)$ and acetaminophen, $16.1 \%(67 / 415)$.

\section{Medication regimen complexity}

The MRCI in the sample showed a mean of $18.2( \pm 9.6)$, ranging from 2.0 to 53.5. The index was higher in the women, with a mean of $19.6( \pm 9.1)$, and $16.1( \pm 9.9)$ in men $(\mathrm{p}<0.001)$. Table 3 shows the sections of the medication complexity index and mean values.

MRCI was higher as the number of drugs increased $(\mathrm{r}=0.879$, CI $99 \%, \mathrm{p}<0.001)$. This was not a rule for every single case, however, as some individuals had high scores that were not related to a large number of drugs, but rather to more complex tasks to be performed. There was considerable variation in MRCI scores within regimens with the same number of drugs (Fig. 1).

Of the factors that contributed to complexity, schedule was the most relevant to the final score $(r=0.922)$, followed by pharmaceutical form $(\mathrm{r}=0.768)$, and additional instructions $(\mathrm{r}=0.742)(\mathrm{CI} 99 \%(\mathrm{p}<0.001))$.
In the elderly people receiving from 1 to 5 different drugs, the total MRCI score was $6.6( \pm 2.9)$ while in those receiving from 6 to 20 was $20.2( \pm 8.9)$ (CI $99 \%$ $(\mathrm{p}<0.001))$.

Most of the medications (84.5\%) were taken in only one form (tablet/capsule). About $99.3 \%$ of the patients were taking at least one tablet or capsule. The most common dosing frequency was one medication twice daily $(31.8 \%)$.

Where additional instructions were concerned, $22.7 \%$ of the patients followed at least one, $22.2 \%$ at least two and $40 \%$ three or more. The most frequent instructions were to break or crush the tablets $(27 \%)$ and take or use the medications at a specific time. The mean scores are shown in Table 4.

\section{Discussion}

An aging population with a lack of family support leads to more institutionalized elderly people [22]. Medication management was found to rarely include in this population a critical analysis or review of regimens and is usually restricted to distribution.

The elderly population (living at home or in an institution) is particularly vulnerable to adverse drug reactions, drug interactions and low compliance to chronic medication and it is essential to characterize drug therapy complexity in order to do something to simplify it [23].

Validated tools can assess medication regimen complexity. We chose the MRCI for this study, because it is a comprehensive instrument that includes 65 items related not only to prescription data (number of medications, dosage forms), but also to dose frequency and instructions on how to take the medication (e.g. break tablet) $[15,16]$.

The MRCI has been adapted to Portuguese for Brazil by George [15] and Melchiors [16], but not for Portugal. From the point of view of the authors this is not a limitation because even if the language is slightly different, the tool is to be used by health care professionals, not by patients, and no problems related with the use of the instrument have been reported during the study.

\section{Medication profile}

Mean consumption in the sample was 8.2 drugs per individual per day. This high consumption is similar to results found in other studies of elderly peoples' pharmacotherapy [24]. The polypharmacy observed in this study was also similar to that found in the majority of studies performed in this age group. Kaufman [25] in the USA found that $57 \%$ of women aged 65 and over took five or more drugs and $12 \%$ took ten or more. In a study conducted in eight 
Table 4 Medication regimen complexity index by item (mean scores)

\begin{tabular}{|c|c|c|c|c|}
\hline $\begin{array}{l}\text { Section A } \\
\text { dosage forms }\end{array}$ & Mean & $\begin{array}{l}\text { Section B } \\
\text { Dosing frequency }\end{array}$ & Weight & Mean \\
\hline Oral & & Once daily & 1 & 5.2 \\
\hline Capsules/tablets & 1 & Once daily prn & 0.5 & 0 \\
\hline Gargles/mouthwashes & 0 & Twice daily & 2 & 3.4 \\
\hline Gums/lozenges & 0 & Twice daily prn & 1 & 0.1 \\
\hline Liquids & 0.4 & Three times daily & 3 & 1.5 \\
\hline Powders/granules & 0.5 & Three times daily prn & 1.5 & 0 \\
\hline Sublingual sprays/tabs & 0 & Four times daily & 4 & 0.2 \\
\hline Topical & & Four times daily prn & 2 & 0 \\
\hline Creams/gels/ointments & 0.3 & $\mathrm{q} 12 \mathrm{~h}$ & 2.5 & 0.1 \\
\hline Dressings & 0 & q $12 \mathrm{~h} \mathrm{prn}$ & 1.5 & 0 \\
\hline Paints/solutions & 0 & $\mathrm{q} 8 \mathrm{~h}$ & 3.5 & 0 \\
\hline Pastes & 0 & q $8 \mathrm{~h} \mathrm{prn}$ & 2 & 0 \\
\hline Patches & 0.2 & $\mathrm{q} 6 \mathrm{~h}$ & 4.5 & 0 \\
\hline Sprays & 0 & q $6 \mathrm{~h}$ prn & 2.5 & 0 \\
\hline Ear, eye and nose & & $\mathrm{q} 4 \mathrm{~h}$ & 6.5 & 0 \\
\hline Ear drops/creams/ointments & 0 & q 4 h prn & 3.5 & 0 \\
\hline Eye drops & 0.3 & $\mathrm{q} 2 \mathrm{~h}$ & 12.5 & 0 \\
\hline Eye gels/ointments & 0 & q 2 h prn & 6.5 & 0 \\
\hline Nasal drops/cream/ointment & 0 & $\mathrm{prn} / \mathrm{sos}$ & 0.5 & 0.2 \\
\hline Nasal spray & 0 & On alternate days or less frequently & 2 & 0.5 \\
\hline \multirow[t]{2}{*}{ Inhalation } & & Oxygen prn & 1 & 0 \\
\hline & & Oxygen $<15 \mathrm{~h}$ & 2 & 0 \\
\hline Accuhalers & 0.1 & Oxygen $>15 \mathrm{~h}$ & 3 & 0 \\
\hline Aerolizers & 0.1 & Total for Section B & 11.2 & \\
\hline Metered dose inhalers & 0.2 & Section $C$ & Weight & Mean \\
\hline Nebuliser & 0.1 & Additional directions & & \\
\hline Oxygen/concentrator & 0.1 & & & \\
\hline Turbuhalers & 0.1 & & & \\
\hline Other DPIs & 0 & Break or crush tablet & 1 & 0.7 \\
\hline Others & & Dissolve tablet/powder & 1 & 0.2 \\
\hline Dialysate & 0 & Multiple units at one time (e.g. 2 tabs, 2 puffs) & 1 & 0.3 \\
\hline Enemas & 0 & & & \\
\hline Injections & & Variable dose & 1 & 0 \\
\hline Prefilled & 0.1 & (e.g. 1-2 caps, 2-3 puffs) & & \\
\hline Ampoules/vials & 0.1 & Take/use at specified time/s (e.g. mane, nocte, 8 AM) & 1 & 1 \\
\hline Pessaries & 0 & Relation to food (e.g. pc, ac, with food) & 1 & 0.3 \\
\hline Patient controlled analgesia & 0 & Take with specific fluid & 1 & 0 \\
\hline Suppositories & 0 & Take/use as directed & 2 & 0.4 \\
\hline Vaginal creams & 0 & Tapering/increasing dose & 2 & 0 \\
\hline \multirow[t]{2}{*}{ Total for Section A } & 3.6 & $\begin{array}{l}\text { Alternating dose (e.g. one mane and two nocte, } \\
\text { one/two on alternate days) }\end{array}$ & 2 & 0.5 \\
\hline & & Total for Section $C$ & 3.4 & \\
\hline \multicolumn{5}{|c|}{ Medication complexity index (Section A + Section B + Section C) } \\
\hline
\end{tabular}


European countries, Fialová [26] observed that $51 \%$ of elderly people were taking six or more drugs a day. SicrasMainar [27] found higher consumption of oral forms $(84.5 \%)$.

Castellar [17] obtained similar results for medication profiles. By therapeutic groups, he found that the medications taken most were for the cardiovascular system $(27.3 \%)$, followed by the nervous system $(21.6 \%)$ and the alimentary tract and metabolism (14.1\%) [17].

Similar results were also obtained by Muir [28], in which the active substance that individually appeared most often in medication record was, acetylsalicylic acid 100 and $150 \mathrm{mg}$, found in $31.8 \%$ of cases.

\section{Medication regimen complexity}

Older people, especially women, are more prone to polypharmacy due to multiple chronic conditions that they usually suffer and their greater propensity for taking medications. In the current study, however, only gender contributed significantly to the complexity of therapeutic schemes [15].

The average complexity index of the sample was 18.2. This figure is different from the results found in other published studies that used the same instrument: Oosthuizen [29] obtained a figure of 19.3 in an age range of 60-69 years, and Correr [30] found an average complexity of 15.5 in individuals older than 30 . In our study, the older population taking a large number of medications may explain the average complexity index figure. However, a greater number of medications does not always mean a higher complexity index. This confirms the index's ability to emphasize the different complexity of regimens with the same number of drugs, and demonstrates that the MRCI goes beyond the mere quantification of drugs [15, 28].

The correlation between the complexity index's total ratio and its three sections (A, B and C) in particular shows direct proportionality. In other words, a higher complexity index is the direct result of individual growth in each section [15].

As the MRCI is an open-ended index, with no maximum value, no articles or authors were found who tried to establish a cut-off, a figure related to negative health outcomes and the need to intervene. However, several studies have investigated the positive impact of intervention aimed at reducing the complexity of medication regimens whenever possible [18, 31].

Like Stange [18], the most relevant factors found for complexity were schedule (section B of the MRCI-frequency of doses), followed by pharmaceutical forms and additional instructions. Here, specialized intervention by a healthcare professional, particularly a pharmacist, may be more effective in reducing it in a medication review [18].
Khalil [32] demonstrated the importance of the doctorpharmacist collaboration in the management of residents' medications in aged care facilities from the point of view of the patient safety.

The assessment of regimen complexity using the MRCI may be an effective tool for professionals managing the medication of the elderly in order to promote rational use of drugs. In a study on the effect of medication reviews in institutionalized elderly, Zermansky [33] demonstrated its advantages, when performed by specialized professionals, not only in terms of patient health outcomes, but also of costs. However, the additional time, effort, and professional training needed to calculate it may decrease its use and popularity [13]. In 2013 McDonald et al. [11] developed a tool that for automating calculation of the MRCI score and accelerating evaluation of its potential.

\section{Conclusion}

The literature highlights medication complexity as a factor likely to impact negatively on patient compliance and ultimately treatment efficacy and safety, and should therefore be considered as a particularly important aspect in the elderly population.

This study evaluated medication complexity in institutionalized male and female patients taking different medications and patients with different underlying conditions.

Medication complexity evaluated by the MRCI index was found to be high (average of 18.2), and higher in females, suggesting the need for further intervention. It was mainly related to the number of medications taken chronically, and also to dose frequency.

Of the factors that contributed to complexity, schedule was the most relevant to the final score, followed by pharmaceutical forms and additional instructions, in which a medication review by a healthcare professional may be more effective in reducing it.

The MRCI showed good evidence of classifying regimen complexity better than a simple medication count, in the studied population. It proved to have potential in the routine to help reduce medication regimen complexity by identifying factors that contribute to this complexity in elderly care institutions, thereby promoting compliance and avoiding medication errors.

Given the large body of evidence that regimen complexity is an important predictor of treatment burden, medication adherence and outcomes, more attention should be devoted to this aspect.

Health care professionals and particularly pharmacists should be trained to use the MRCI, in order to assess the complexity of medication regimen of their older patients, and try to found solutions to reduce it, whenever possible. 
Acknowledgments Special acknowledgment to the cooperation of nursing homes that participated in data Collection.

Funding The authors did not receive any financial support.

Conflicts of interest None.

\section{References}

1. United Nations. World Population Prospects: The 2010 Revision [Internet]. Popul. Div. 201 Available from: http://www.un.org/ esa/population/.

2. Statistics Portugal. Census 2011-Provisional Results [Internet]. Censos 2011. 2011. Available from: http://www.ine.pt/xportal/ xmain?xpid=INE\&xpgid=ine_destaques\&DESTAQUESdest_boui= 129675729\&DESTAQUESmodo $=2$.

3. Bloom D, Boersch-Supan A. Population aging: facts, challenges and responses [Internet]. Boston; 2011. Available from: https:// www.hsph.harvard.edu/pgda/WorkingPapers/2011/PGDA_WP_ 71.pdf.

4. World Health Organization. Healthy ageing-practical pointers on keeping well [Internet]. 2005. Available from: http://www. wpro.who.int/publications/docs/HealthyAgeingFinal.pdf.

5. Economist Intelligence Unit. Healthcare strategies for an ageing society [Internet]. 2009. Available from: http://graphics.eiu.com/ upload/eb/Philips_Healthcare_ageing_3011WEB.pdf.

6. World Health Organization. Good health adds life to yearsGlobal brief for World Health Day 2012 [Internet]. Geneva; 2012. Available from: http://whqlibdoc.who.int/hq/2012/WHO_ DCO_WHD_2012.2_eng.pdf.

7. Mosegui GBG, Rozenfeld S, Veras RP, Vianna CMM. Avaliação da qualidade do uso de medicamentos em idosos. Rev Saú Públ. 1999;33(5):437-44.

8. Murray MD, Callahan CM. Improving medication use for older adults: an integrated research agenda. Ann Intern Med. 2003; 139(5 Pt 2):425-9.

9. Mannesse CK, Derkx FH, de Ridder MA, Man in't Veld AJ, van der Cammen TJ. Adverse drug reactions in elderly patients as contributing factor for hospital admission: cross sectional study. BMJ. 1997;315(7115):1057-8.

10. Hanlon JT, Artz MB, Pieper CF, Lindblad CI, Sloane RJ, Ruby $\mathrm{CM}$, et al. Inappropriate medication use among frail elderly inpatients. Ann Pharmacother. 2004;38(1):9-14.

11. McDonald MV, Peng TR, Sridharan S, Foust JB, Kogan P, Pezzin LE, et al. Automating the medication regimen complexity index. JAMIA. 2013;20(3):499-505.

12. Ingersoll KS, Cohen J. The impact of medication regimen factors on adherence to chronic treatment: a review of literature. J Behav Med. 2008;31(3):213-24.

13. Mansur N, Weiss A, Beloosesky Y. Looking beyond polypharmacy: quantification of medication regimen complexity in the elderly. Am J Geriatr Pharmacother [Internet]. 2012 Aug [cited 2013 Dec 14];10(4):223-9. Available from: http://www.ncbi.nlm. nih.gov/pubmed/22749668.

14. Corsonello A, Pedone C, Lattanzio F, Lucchetti M, Garasto S, Carbone $\mathrm{C}$, et al. Regimen complexity and medication nonadherence in elderly patients. Ther Clin Risk Manag. 2009;5(1):209-16.

15. George J, Phun YT, Bailey MJ, Kong DCM, Stewart K. Development and validation of the medication regimen complexity index. Ann Pharmacother. 2004;38(9):1369-76.
16. Melchiors AC, Correr CJ, Fernández-Llimos F. Translation and validation into Portuguese language of the medication regimen complexity index. Arq Bras Cardiol. 2007;89(4):210-8.

17. Castellar JI, Karnikowski MGO, Vianna LG, Nóbrega OT. Study of the pharmacotherapy prescribed for older-adult in a Brazilian long-term care facility. Acta Med Port. 2007;20:97-105.

18. Stange D, Kriston L, Von-Wolff A, Baehr M, Dartsch DC. Reducing cardiovascular medication complexity in a German university hospital: effects of a structured pharmaceutical management intervention on adherence. J Manag Care Pharm. 2013; 19(5):396-407.

19. Elliott RA. Reducing medication regimen complexity for older patients prior to discharge from hospital: feasibility and barriers. J Clin Pharm Ther [Internet]. 2012 Dec [cited 2013 Dec 29];37(6):637-42. Available from: http://www.ncbi.nlm.nih.gov/ pubmed/22607618.

20. Centre for Home Care Policy and Research. Medication regimen complexity in home health care. [Internet]. 2011 [cited 2013 Dec 27]. Available from: http://toolkit.techandaging.org/2011/03/08/ medication-regime-complexity-in-home-health-care/.

21. Bushardt RL, Massey EB, Simpson TW, Ariail JC, Simpson KN. Polypharmacy: misleading, but manageable. Clin Interv Aging. 2008;3(2):383-9.

22. Chaimowicz F, Greco DB. Dynamics of institutionalization of older adults in Belo Horizonte. Braz Rev Saú Públ. 1999;33(5): 454-60.

23. Hanlon JT, Schmader KE, Ruby CM, Weinberger M. Suboptimal prescribing in older inpatients and outpatients. J Am Geriatr Soc. 2001;49(2):200-9.

24. Oliveira-Martins S, Soares MA, Foppe van Mil JW, Cabrita J. Inappropriate drug use by Portuguese elderly outpatients-effect of the Beers criteria update. Pharm World Sci. 2006;28(5):296-301.

25. Kaufman DW, Kelly JP, Rosenberg L, Anderson TE, Mitchell AA. Recent patterns of medication use in the ambulatory adult population of the United States: the Slone survey. JAMA. 2002;287(3):337-44.

26. Fialová D, Topinková E, Gambassi G, Finne-Soveri H, Jónsson PV, Carpenter I, et al. Potentially inappropriate medication use among elderly home care patients in Europe. JAMA. 2005; 293(11):1348-58.

27. Sicras-Mainar A, de Cambra-Florensa S, Navarro-Artieda R. Consumption of oral analgesics and dosage forms in elderly patients: population-based study. Farm Hosp. 2009;33(3):161-71.

28. Muir AJ, Sanders LL, Wilkinson WE, Schmader K. Reducing medication regimen complexity. J Gen Intern Med. 2001;16(2): $77-82$.

29. Oosthuizen F, Dhoodhat E, Kazi S, Masondo B, Omarjee N. Assessing the complexity of medicine regimens-a pilot study. AJPP. 2011;5(16):1863-6.

30. Correr CJ, Melchiors AC, Fernandez-Llimos F, Pontarolo R. Effects of a pharmacotherapy follow-up in community pharmacies on type 2 diabetes patients in Brazil. Int J Clin Pharm. 2011;33(2):273-80.

31. Elliott RA, O'Callaghan C, Paul E, George J. Impact of an intervention to reduce medication regimen complexity for older hospital inpatients. Int J Clin Pharm. 2013;35(2):217-24.

32. Khalil $\mathrm{H}$. A review of pharmacist recommendations in an aged care facility. Aust J Prim Health. 2011;17(1):35-9.

33. Zermansky AG, Alldred DP, Petty DR, Raynor DK, Freemantle $\mathrm{N}$, Eastaugh J, et al. Clinical medication review by a pharmacist of elderly people living in care homes-randomised controlled trial. Age Ageing. 2006;35(6):586-91. 